Article

\title{
The Shannon Entropy Trend of a Fish System Estimated by a Machine Vision Approach Seems to Reflect the Molar Se:Hg Ratio of Its Feed
}

\author{
Harkaitz Eguiraun ${ }^{1,2, *}$ (1) , Oskar Casquero $^{3}$ and Iciar Martinez ${ }^{2,4,5}$ \\ 1 Department of Graphic Design and Engineering Projects, Faculty of Engineering in Bilbao, \\ University of the Basque Country UPV/EHU, E-48013 Bilbao, Spain \\ 2 Research Center for Experimental Marine Biology and Biotechnology-Plentziako Itsas Estazioa (PiE), \\ University of the Basque Country UPV/EHU, E-48620 Plentzia, Spain; iciar.martinez@ehu.eus \\ 3 Department of Systems Engineering and Automatic Control, Faculty of Engineering in Bilbao, \\ University of the Basque Country UPV/EHU, E-48013 Bilbao, Spain; oskar.casquero@ehu.eus \\ 4 IKERBASQUE Basque Foundation for Science, E-48013 Bilbao, Spain \\ 5 Norwegian College of Fishery Science, Faculty of Biosciences, Fisheries and Economics, \\ University of Tromsø-The Arctic University of Norway, N-9019 Tromsø, Norway \\ * Correspondance: harkaitz.eguiraun@ehu.eus; Tel.: +34-946-017-218
}

Received: 20 November 2017; Accepted: 24 January 2018; Published: 29 January 2018

\begin{abstract}
The present study investigates the suitability of a machine vision-based method to detect deviations in the Shannon entropy (SE) of a European seabass (Dicentrarchus labrax) biological system fed with different selenium:mercury (Se:Hg) molar ratios. Four groups of fish were fed during 14 days with commercial feed (control) and with the same feed spiked with 0.5, 5 and $10 \mathrm{mg}$ of $\mathrm{MeHg}$ per $\mathrm{kg}$, giving Se:Hg molar ratios of 29.5 (control- $\left.\mathrm{C}_{1}\right) ; 6.6,0.8$ and $0.4\left(\mathrm{C}_{2}, \mathrm{C}_{3}\right.$ and $\left.\mathrm{C}_{4}\right)$. The basal SE of $\mathrm{C}_{1}$ and $\mathrm{C}_{2}(\mathrm{Se}: \mathrm{Hg}>1)$ tended to increase during the experimental period, while that of $\mathrm{C}_{3}$ and $\mathrm{C}_{4}$ $(\mathrm{Se}: \mathrm{Hg}<1)$ tended to decrease. In addition, the differences in the $\mathrm{SE}$ of the four systems in response to a stochastic event minus that of the respective basal states were less pronounced in the systems fed with Se:Hg molar ratios lower than one $\left(C_{3}\right.$ and $\left.C_{4}\right)$. These results indicate that the SE may be a suitable indicator for the prediction of seafood safety and fish health (i.e., the Se:Hg molar ratio and not the $\mathrm{Hg}$ concentration alone) prior to the displaying of pathological symptoms. We hope that this work can serve as a first step for further investigations to confirm and validate the present results prior to their potential implementation in practical settings.
\end{abstract}

Keywords: entropy; seabass; mercury; selenium; fish welfare; machine vision; contaminant detection; biological warning systems; system perturbation; environmental monitoring

\section{Introduction}

The forecasted growth for the world human population estimates that there will be somewhere between 9.6 and 12.3 billion people in the year 2100 [1]. As a consequence, one of the main global concerns is to improve and optimize the food production systems, with particular emphasis on seafood [2-4], expected to be a main provider of key nutrients such as high quality proteins, omega-3 fatty acids, trace elements and vitamins [4,5].

Unfortunately, and as a result of human activities, the aquatic environment is contaminated with a variety of pollutants, including mercury $(\mathrm{Hg})$, whose organic form (methylmercury, $\mathrm{MeHg}$ ) is currently considered as one of the regulated contaminants of concern [6] albeit only in seafood [7]. The acceptable maximum level of $\mathrm{Hg}$ in most fish products is $0.5 \mathrm{mg} / \mathrm{kg}$ wet weight, except for long lived species placed high in the trophic chain for which a level is set at $1.0 \mathrm{mg} / \mathrm{kg}$ wet weight. 
It is not possible to control the levels of $\mathrm{MeHg}$ in the tissues of captured fisheries, but given that the contaminant is accumulated in the food chain, a strict control of the water quality and the feeds' composition should minimize or eliminate the risk of high $\mathrm{MeHg}$ levels in farmed fish. However, this introduces a new challenge, since nowadays it is not possible to completely substitute some marine feed ingredients (in particular those from fatty fish) by others of terrestrial origin without seriously compromising the health and welfare of the fish as well as its nutritional value [8]. Therefore, the maximum level of $\mathrm{Hg}$ in feeds destined for fish farming has been set to $0.227 \mathrm{mg} \mathrm{Hg}$ per kg dry feed [9]. Interestingly, it has been proposed that the toxicity of $\mathrm{Hg}$ is exerted through its ability to interact with selenium (Se) [10], which in turn plays a critical role to maintain the cellular redox potential. Thus, a molar excess of $\mathrm{Hg}$ over Se will mean that the cell does not have enough Se to maintain its redox potential and pathological alterations characteristic of $\mathrm{Hg}$ poisoning will take place. If, on the other hand, there is Se in excess, then the negative effect of $\mathrm{Hg}$ will be neutralized and there will remain enough Se to allow the cells to perform satisfactorily [10,11]. Unfortunately, it is not yet common to refer to the Se:Hg molar ratio when evaluating seafood safety.

Novel, on-line, non-destructive, efficient monitoring systems will also be in demand to ensure the safety and welfare of farmed fish. Targeting this purpose, our research group has proposed the use of fish of the same species being cultivated as a Biological Warning System (BWS) in order to detect the introduction of undesirable contaminants in their environment and/or feed during production [12]. There are several reasons to propose the use of BWS: one is that the organisms themselves will act as integrators of all the substances they are exposed to (i.e., both listed and monitored and new and unexpected substances), another is that contaminants usually occur in mixtures and that the effect of the mixture is not necessarily the sum of the effects of each component alone [10].

Our previous works, based on the principle of a BWS, indicated that the seabass system's SE was sensible to the presence of $\mathrm{MeHg}$ in the environmental water [13] and that the trend of the SE-values over time gave information of relevance to assess the system's recovery from a temporary contamination [14]. However, the most common route of entrance of $\mathrm{MeHg}$ in the fish tissues is through the feed. Therefore, the present work was designed to (i) quantify the response of D. labrax systems to feeds containing four different concentrations of MeHg during 14 days and (ii) to evaluate the suitability of the systems' (ii-a) basal SE, (ii-b) SE of the response to a stochastic event and (ii-c) evolution of these two SE values over time, to verify the presence of MeHg in the system.

\section{Materials and Methods}

The experimental procedure was approved by The Ethical Committee for Animal Welfare No. CEBA/285/2013MG.

\subsection{Experimental Cases}

Four European seabass (Dicentrarchus labrax) experimental cases were monitored every second day during 14 days. Each case consisted of 7 fish and they were fed: the control group $\left(C_{1}\right)$ standard commercial pellets, and the exposed groups $\left(C_{2}, C_{3}\right.$ and $\left.C_{4}\right)$ feed spiked with $0.5,5$ and $10 \mathrm{mg}$ $\mathrm{MeHg} / \mathrm{kg}$ respectively. In order to minimize the stress to the fish, the video recording was performed every second day, i.e., on the 2 nd, 4 th, 6 th, 8 th, 10 th, 12 th and 14 th day. The visual and environmental conditions in each of the four tanks, as well as the biomass, were maintained as similar as possible (Table 1). Prior to the beginning of the exposure, the fish were acclimated for 3 days to the tanks. No mortality or abnormal behavior was observed during the experimental period. 
Table 1. Data on the fish cases showing the weight at the beginning and at the end of the experiment, and the $\mathrm{Hg}$ and Se contents in the feeds administered to each case. Each case/tank had 7 fish.

\begin{tabular}{|c|c|c|c|c|c|c|}
\hline \multirow{2}{*}{ Case } & \multicolumn{2}{|c|}{ Weight (g) Avg. \pm Std. } & \multirow{2}{*}{$p$ Value $*$} & \multicolumn{2}{|c|}{$\mathrm{mg} \mathrm{Hg} / \mathrm{kg}$ Feed } & \multirow{2}{*}{$\frac{\text { Feed Molar Ratio }}{\text { Se:Hg }{ }^{*}}$} \\
\hline & Day 0 & Day 14 & & Spiked & Measured ** & \\
\hline $\mathrm{C}_{1}$ & $141.6 \pm 19.2$ & $185.5 \pm 40.4$ & $<0.05$ & 0 & 0.10 & 29.54 \\
\hline $\mathrm{C}_{2}$ & $138.6 \pm 34.9$ & $180.2 \pm 10.8$ & $<0.05$ & 0.4 & 0.47 & 6.57 \\
\hline $\mathrm{C}_{3}$ & $141.6 \pm 18.2$ & $144.2 \pm 24.4$ & n.s. & 4 & 3.9 & 0.82 \\
\hline $\mathrm{C}_{4}$ & $144.00 \pm 22.5$ & $162.9 \pm 32.1$ & n.s. & 8 & 6.7 & 0.41 \\
\hline
\end{tabular}

${ }^{*} p$ value using the Student's $t$-test, 1 tail, not paired data and equal or different variance; n.s. $=$ not statistically significant difference; ${ }^{* *}$ The actual $\mathrm{Hg}$ and Se concentrations in the feeds were determined by Inductively Coupled Plasma Mass Spectrometry (ICP-MS) in our laboratory by Dr. José Antonio Carrero. The Hg concentration in the commercial feed was within the legal limit, which is $0.227 \mathrm{mg} \mathrm{Hg} / \mathrm{kg}$ feed [9].

\subsection{Experimental Set Up and Spiking of the Feed}

The experimental set up has been described in [13]. In short, the fish were placed in 4 tanks $(100 \mathrm{~cm} \times 100 \mathrm{~cm} \times 90 \mathrm{~cm})$ filled up to $80.5 \mathrm{~cm}$ of height with $810 \mathrm{~L}$ of aerated circulating seawater. Each tank was under direct artificial light $(2 \times 58 \mathrm{~W}$ and $5200 \mathrm{~lm})$ to avoid shadows, with a $12 \mathrm{~h} / 12 \mathrm{~h}$ dark/light photoperiod. The fish were fed INICIO Plus from BioMar ( $56 \%$ crude protein, $18 \%$ crude fat) once a day following the manufacturer's specifications for their size, weight and water temperature. The $\mathrm{MeHg}$ doses were selected to reflect realistic contents of $\mathrm{Hg}$ in fish (for example $4.54 \mathrm{ppm} \mathrm{Hg}$ have been reported in sandbar shark (Carcharhinus plumbeus) [15]).

The contaminated feeds were prepared as follows: methylmercury(II) chloride $\left(\mathrm{CH}_{3} \mathrm{HgCl}\right.$; Sigma-Aldrich, product number 442534, $\mathrm{Mw}=251.08$ ) was first dissolved in DMSO to a concentration of $250 \mu \mathrm{g} \mathrm{MeHg} / \mu \mathrm{L}$ and then diluted with $99 \%$ ethanol to $125 \mu \mathrm{g} \mathrm{MeHg} / \mu \mathrm{L}$. This solution was further diluted with $99 \%$ ethanol to produce $10 \mathrm{~mL}$ of three solutions: solution $\mathrm{A}(0.25 \mu \mathrm{g} \mathrm{MeHg} / \mu \mathrm{L})$, solution B $(0.125 \mu \mathrm{g} \mathrm{MeHg} / \mu \mathrm{L})$ and solution C $(0.0125 \mu \mathrm{g} \mathrm{MeHg} / \mu \mathrm{L})$. Three batches of contaminated feed were prepared by mixing $175 \mathrm{~g}$ of feed with $7 \mathrm{~mL}$ of solution $\mathrm{A}$, solution $\mathrm{B}$ or solution $\mathrm{C}$ as follows: the trays were placed inside a hood containing $175 \mathrm{~g}$ of feed each, then $7 \mathrm{~mL}$ of the each $\mathrm{MeHg}$ solution were pipetted to its corresponding tray and the pellets and the $\mathrm{MeHg}$ solution were carefully mixed to ensure an even blending of the $\mathrm{MeHg}$ containing ethanol solution and the pellets. The trays were covered and left for 3 days inside the hood. Twice a day, each tray was uncovered, its contents mixed and covered again. At the end of the third day, the pellets in the trays appeared dry and we considered that the MeHg had been absorbed by the pellets. This produced three $175 \mathrm{~g}$ batches of contaminated feed containing, theoretically 10, 5 and $0.5 \mu \mathrm{g} \mathrm{MeHg} / \mathrm{g}$ feed respectively.

Relevant seawater parameters were measured daily prior to feeding. The values, considered optimal, are shown in Table 2. $\mathrm{O}_{2}$ saturation was measured with a JBL $\mathrm{O}_{2}$ kit, salinity with a HANNA HI98192 meter, $\mathrm{NH}_{3}$ with a Sera $\mathrm{NH}_{4}-\mathrm{NH}_{3} \mathrm{kit}$, $\mathrm{pH}$ with a Sera $\mathrm{pH}$ Kit and temperature with a mercury thermometer. Water flow was estimated based on the intake-water pump load. The water was circulating continuously and it was halted only during the recording periods to allow for good quality video images.

Table 2. Seawater parameters during the experimental period.

\begin{tabular}{cc}
\hline Parameter & Value \\
\hline Temperature & $16.9-18.5^{\circ} \mathrm{C}$ \\
$\mathrm{pH}$ & $7.76-7.93$ \\
$\mathrm{NH}_{3}$ & $0.0 \mathrm{mg} / \mathrm{L}$ \\
Water flow & $0.54 \mathrm{~m}^{3} / \mathrm{h}$ \\
Salinity & $33 \mathrm{~g} / \mathrm{L}$ \\
$\mathrm{O}_{2}$ Saturation & $>80 \%$ \\
\hline
\end{tabular}




\subsection{Video Recording Procedure}

Video recording was performed every second day as described in [13]. As mentioned above, water circulation and air bubbling were halted immediately before the initiation of the $30 \mathrm{~min}$ video recording window. During those $30 \mathrm{~min}$, two video clips of $3.5 \mathrm{~min}$, each corresponding respectively to the basal state and to the response of the fish to a stochastic event, which was a sudden hit in the tank that took place in the 30th s of the recording, were analysed. The procedure is illustrated in Figure 1.

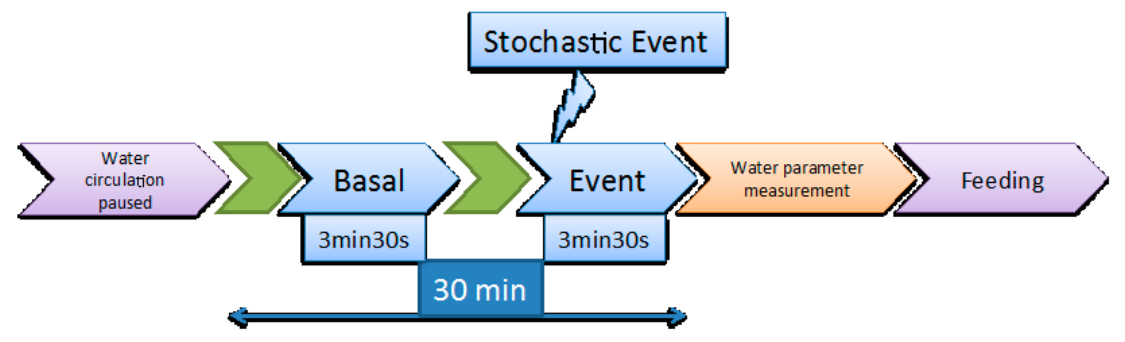

Figure 1. Schematic representation of the video recording procedure.

Data acquisition was done by video camera recording using the same experimental setup described in Eguiraun et al. [13,14]. Summarizing, a GoProHero3 camera with underwater housing was used inside each tank. The raw data were recorded with a $1080 \mathrm{p}$ high definition format, 24 frames per second (fps) and 16:9 video size and the videos were locally stored in SanDisk $32 \mathrm{~Gb}$ UltraMicroSDHCTM (Class 10) secure cards in each camera.

\subsection{Video Data Processing, Trajectory Estimationg and Shannon Entropy (SE) of the Trajectories}

The procedure is explained in detail in publications $[13,14]$ and summarized in Figure 2. In short, once the two video clips ( 1 basal and 1 response per tank and per day) were located in the $30 \mathrm{~min}$ recording, they were transformed into a 640 pixel $\times 480$ pixel format image sequences at $24 \mathrm{fps}$ using the iMovie commercial software. Subsequent image and feature extraction were carried out with MATLAB R2014a (MathWorks Inc., Natick, MA, USA) running on a MacBookPro 2.6 GHz Intel Core i7 laptop with a SSD storage disk and $16 \mathrm{~Gb}$ of RAM.

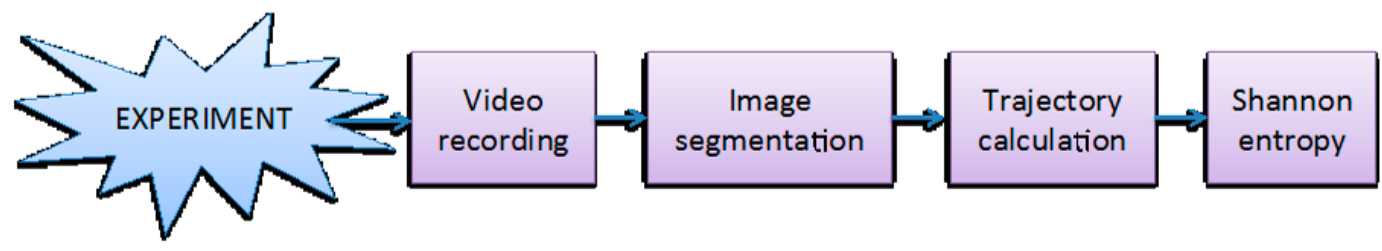

Figure 2. Schematic representation of the data acquisition and processing workflow. For further information see publications $[13,14]$.

The trajectory of the fish cluster's centroid was initially built by computing the elements centre's in every single frame, but this led to a very noisy signal. The noise of the signal was reduced by calculating the cluster's centroid applying the K-means algorithm to the number of elements in each frame using the centres of the elements in the first frame as input coordinates. The trajectories in $X$ and $\mathrm{Y}$ were analysed in the same format they were obtained, although they have different scale dimensions. $\mathrm{X}$ trajectories have dimension from 0 to 640 and $\mathrm{Y}$ trajectories have dimension from 0 to 480 due to the $640 \times 480$ pixel image size. The results indicated that analysing the raw trajectories leads to satisfactory results and differences were not found between the results obtained analysing the raw and the normalized trajectories. However, and with the purpose of building a more robust algorithm for future applications, the $X$ and $Y$ trajectories presented in the current work were normalized using the Z-score technique. 
Finally, the entire image sequences (corresponding to the two 3.5 min video clips) for both the basal and the response to the event were analyzed computing the SE entropy [16] of the trajectory signals of the clusters' centroid for both axis, $\mathrm{X}$ and $\mathrm{Y}$.

SE has found many applications including the evaluation of chaoticness of dynamic systems of arbitrary geometrical shapes [17], redundancy in the English language [16,18] and the complexity of fish trajectories $[13,14,19]$. In the present work, the SE is used with the sole purpose of characterizing the trajectory signals of each experimental case and performing comparisons among them. We do not have a biological interpretation of what the SE really means in our particular case; for example, whether the fish would move more or less, higher or lower in the water column, clustering together or not, aspects which become complicated by the technical issues already described in our previous work [13] including those related to the 2D analysis of a 3D phenomenon and image segmentation. In any case, we do not intend to use the SE in order to characterize the behavior of the fish or their spatial distribution, which are different issues and would require a different methodological approach.

The SE was formulated by Shannon $[16,18]$ and it is calculated by the equation:

$$
\mathrm{H}(\mathrm{X})=-\sum_{\mathrm{x}_{\mathrm{i}} \in \Theta} \mathrm{p}\left(\mathrm{x}_{\mathrm{i}}\right) \log \mathrm{p}\left(\mathrm{x}_{\mathrm{i}}\right)=-\mathrm{E}\left[\log \mathrm{p}\left(\mathrm{x}_{\mathrm{i}}\right)\right]
$$

where $X$ represents a random variable with a set of values $\Theta$ and probability mass function $p\left(x_{i}\right)=\operatorname{Pr}_{r}\left\{X=x_{i}\right\}, x_{i} \in \Theta$, and $E$ represents the expectation operator. Note that $p \log p=0$ if $\mathrm{p}=0$.

\subsection{Statistics}

Statistics were computed using R software.

\section{Results and Discussion}

Large individual variation in responses to environmental changes is usually encountered in biological systems (see [20] and references therein). The current system was no exception, and as shown in Table 1, large variations were noticeable in the weight distributions within each case. It is interesting to note that only fish in $C_{1}$ and $C_{2}$ experimented a significant $(p<0.05)$ increase of over $30 \%$ of their initial weight, while the increase in weight in $C_{3}$ and $C_{4}$ was not significant and lower than $14 \%$. This is understandable since organisms subject to stresses have to use a significant amount of their energy to keep their homeostasis and this usually reflects on impaired growth [21,22].

Large variations were also registered in the measured SE values (Table 3), including among measurements performed on the 2nd day, when differences due to the MeHg treatments should have been unnoticeable. Therefore, in order to make comparisons easier, the SE values of the four cases were normalized with respect to the earliest values registered which were estimated on the 2nd day and considered to be $100 \%$ of the SE.

Table 3. Absolute $S E$ values per experimental day, experimental case $\left(C_{1}, C_{2}, C_{3}\right.$ and $\left.C_{4}\right)$ and for the basal state (Basal) and for the response (Resp.) to the introduced event.

\begin{tabular}{ccccccccc}
\hline \multirow{2}{*}{ Day } & \multicolumn{2}{c}{$\mathrm{C}_{\mathbf{1}}$} & \multicolumn{2}{c}{$\mathrm{C}_{\mathbf{2}}$} & \multicolumn{2}{c}{$\mathrm{C}_{\mathbf{3}}$} & \multicolumn{2}{c}{$\mathrm{C}_{\mathbf{4}}$} \\
\cline { 2 - 9 } & Basal & Resp. & Basal & Resp. & Basal & Resp. & Basal & Resp. \\
\hline 2nd & 4.37 & 5.00 & 5.43 & 6.10 & 5.43 & 5.67 & 5.07 & 4.92 \\
4th & 4.65 & 5.19 & 5.82 & 6.96 & 5.04 & 5.43 & 5.02 & 4.93 \\
6th & 4.99 & 5.83 & 6.43 & 6.74 & 5.52 & 5.34 & 4.43 & 5.06 \\
8th & 4.82 & 5.34 & 6.10 & 6.42 & 4.99 & 5.24 & 5.05 & 5.01 \\
10th & 4.92 & 5.55 & 5.69 & 6.79 & 5.42 & 5.25 & 5.23 & 5.66 \\
12th & 4.81 & 5.53 & 4.90 & 6.21 & 4.59 & 5.11 & 4.88 & 5.41 \\
14th & 5.23 & 5.68 & 5.63 & 5.70 & 4.84 & 5.14 & 4.49 & 4.75 \\
\hline
\end{tabular}


Figures 3 and 4 include the plot of the linear trend of the SE values during the experimental period given the previously proposed potential diagnostic value of such trend $[14,19]$. The left panel of Figure 3 shows the normalized SE of the basal states. The trends of the SE values divided the 4 cases into two groups: $C_{1}$ and $C_{2}$ on one hand, with a normalized SE value usually higher than $100 \%$ and with a tendency to increase and, on the other hand, groups $C_{3}$ and $C_{4}$, with normalized SE values lower than $100 \%$ and with a tendency to decrease, although only the regression lines of $C_{1}$ and $C_{3}$ were statistically significant. The parameters of the linear regression lines of the basal state are shown in Table 4.
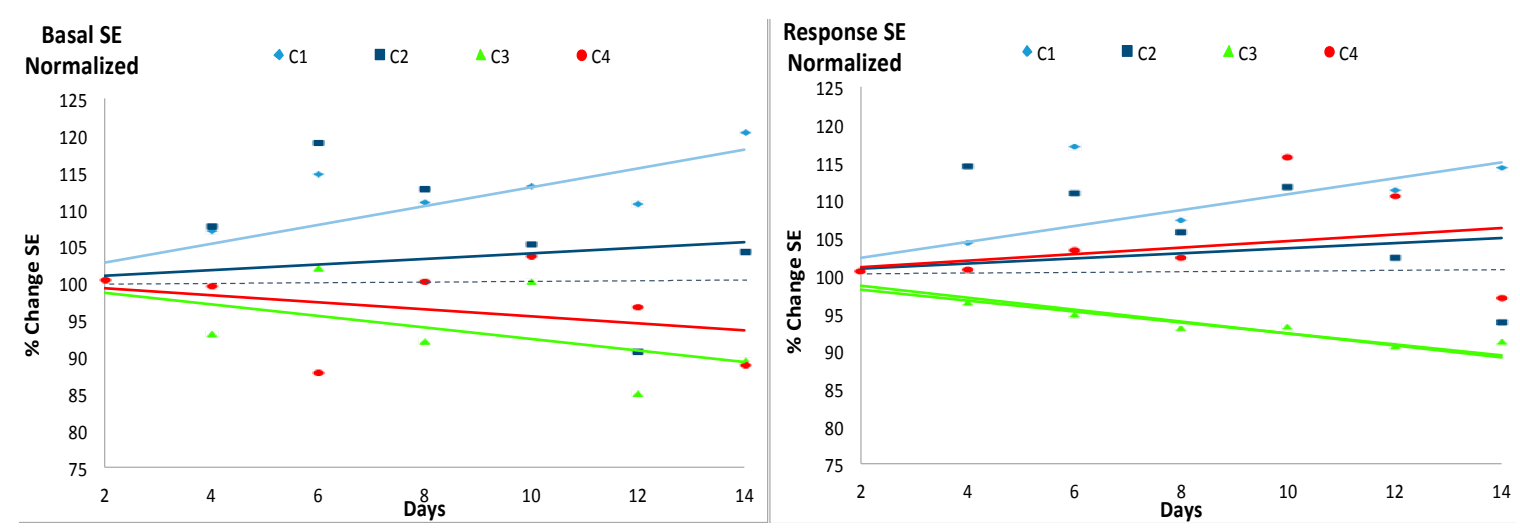

Figure 3. Evolution of the normalized Shannon Entropy (SE) values for the basal state (left) and the response to the event (right) during the 14 experimental days. The four experimental groups $\left(\mathrm{C}_{1}, \mathrm{C}_{2}\right.$, $\mathrm{C}_{3}$ and $\mathrm{C}_{4}$ ) with 7 individuals each are described in Table 1 . Absolute values of the SE are shown in Table 3. The solid lines represent the linear trend of SE from the initial condition at the beginning of the experimental period (normalized SE $=100$ ). For each case, the color of the line is the same as the color of the marker. See Tables 4 and 5 for further information.

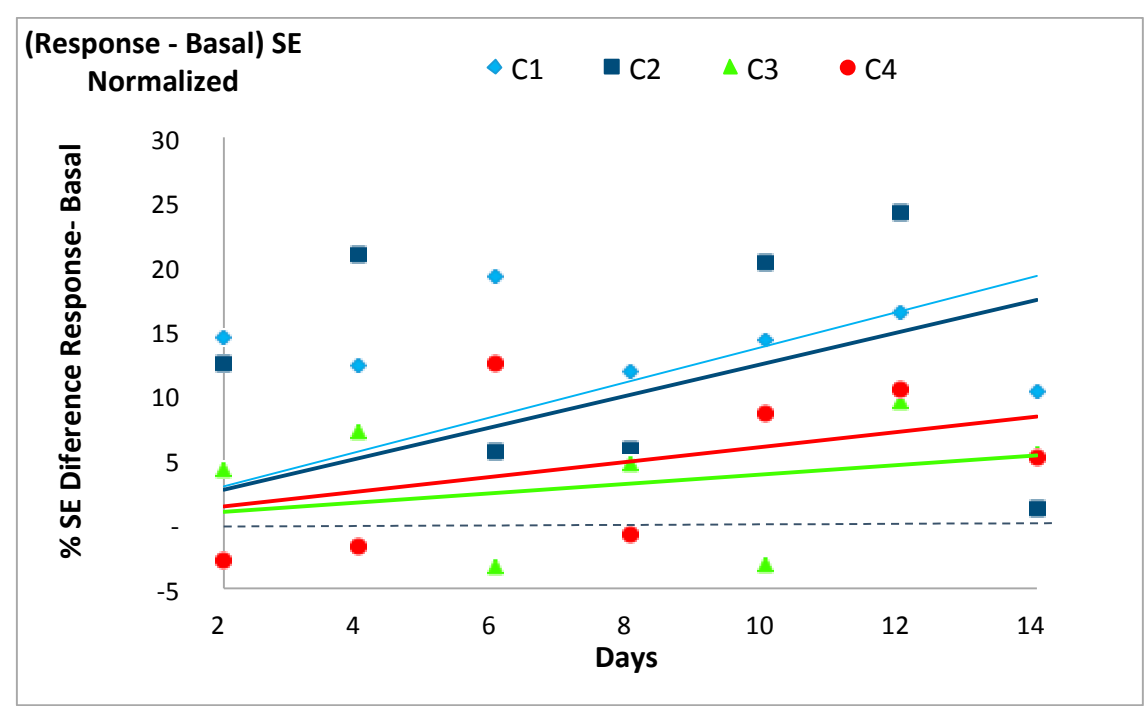

Figure 4. Evolution of the normalized difference between the Shannon Entropy (SE) values for the response to the event minus that of the basal state for each of the four experimental cases $\left(C_{1}, C_{2}\right.$, $\mathrm{C}_{3}$ and $\mathrm{C}_{4}$ ) described in Table 1. See Table 6 for further information. 
Table 4. Estimates of the simple linear regressions $\left(y=\beta_{1} \times x+100\right)$ calculated to observe the trend of the SE (dependent variable, y) over time (independent variable, $x$ ) from the initial condition at the beginning of the experimental period $(\mathrm{SE}=100)$ for the basal states. A significant regression equation was found in $C_{1}(F(1,6)=68.65, p<0.001)$, with an $R^{2}$ of 0.919 . A significant regression equation was not found in $C_{2}$. A significant regression equation was found in $C_{3}(F(1,6)=12.46, p<0.05)$, with an $R^{2}$ of 0.675 . A significant regression equation was not found in $C_{4}$.

\begin{tabular}{|c|c|c|c|c|c|}
\hline & Group & $\beta_{1}$ & Std. Error & $\mathbf{t}$ & $\mathbf{R}^{2}$ \\
\hline \multirow{2}{*}{ Se:Hg $>1$} & $\mathrm{C}_{1}$ & 1.294 & 0.156 & $8.286^{* * *}$ & 0.919 \\
\hline & $\mathrm{C}_{2}$ & 0.398 & 0.418 & 0.952 & 0.131 \\
\hline \multirow{2}{*}{ Se:Hg $<1$} & $\mathrm{C}_{3}$ & -0.760 & 0.215 & $-3.529 *$ & 0.675 \\
\hline & $\mathrm{C}_{4}$ & -0.454 & 0.243 & -1.871 & 0.368 \\
\hline
\end{tabular}

The normalized SE of the response to the event, shown in the right panel of Figure 3 did not display either a clear relationship with the $\mathrm{Hg}$ concentration: in this case however, while the SE values over time of $C_{1}$ were higher than $100 \%$ and with a significant tendency to increase and those of $C_{3}$ were lower than $100 \%$ and with an also significant tendency to decrease, the trends of $C_{2}$ and $C_{4}$ were similar and tending to increase but not in a significant manner. The parameters of the simple linear regression lines of the response to the event are shown in Table 5.

Table 5. Estimates of the simple linear regressions $\left(y=\beta_{1} \times x+100\right)$ calculated to observe the trend of the SE (dependent variable, y) over time (independent variable, $x$ ) from the initial condition at the beginning of the experimental period $(\mathrm{SE}=100)$ for the responses to an event. A significant regression equation was found in $C_{1}(F(1,6)=33.04, p<0.01)$, with an $R^{2}$ of 0.846 . A significant regression equation was not found in $C_{2}$. A significant regression equation was found in $C_{3}(F(1,6)=212.1$, $p<0.001$ ), with an $R^{2}$ of 0.972 . A significant regression equation was not found in $C_{4}$.

\begin{tabular}{|c|c|c|c|c|c|}
\hline & Group & $\beta_{1}$ & Std. Error & $\mathbf{t}$ & $\mathbf{R}^{2}$ \\
\hline \multirow{2}{*}{ Se:Hg $>1$} & $\mathrm{C}_{1}$ & 1.073 & 0.187 & $5.748^{* *}$ & 0.846 \\
\hline & $\mathrm{C}_{2}$ & 0.357 & 0.359 & 0.996 & 0.142 \\
\hline \multirow{2}{*}{ Se: $\mathrm{Hg}<1$} & $\mathrm{C}_{3}$ & -0.773 & 0.053 & $-14.560 * * *$ & 0.972 \\
\hline & $\mathrm{C}_{4}$ & 0.454 & 0.264 & 1.721 & 0.330 \\
\hline
\end{tabular}

In accordance with our previous works $[14,19]$ the SE of each system's basal state was usually lower than its respective $S E$ value in response to the stochastic event, except for two days in $C_{3}$ and three days in $\mathrm{C}_{4}$. The differences between the response and the basal SE values for each case tended to increase with time, with a larger increase (i.e., steeper slopes of the trend lines) for $C_{1}$ and $C_{2}$ (slopes 1.38 and 1.25) than for $C_{3}$ and $C_{4}$ (slopes 0.39 and 0.60), as shown in Figure 4 and Table 6. Only the regression line of $\mathrm{C}_{3}$ was not statistically significant.

The division of the basal SE evolution of the four systems into two groups, $C_{1}$ and $C_{2}$ on one hand and $C_{3}$ and $C_{4}$ on the other, seems to indicate that the relevant factor to understand such responses as the growth of the fish and the evolution of the SE for each of the four experimental cases is the Se:Hg molar ratio of the feed $\left(C_{1}\right.$ and $C_{2}$ had a higher than 1 ratio and $C_{3}$ and $C_{4}$ had a lower than 1 ratio) and not the $\mathrm{MeHg}$ dose alone. If only the dose of $\mathrm{Hg}$ had been the relevant factor, there should have been a dose-related evolution of the $\mathrm{SE}$ of the four groups according to the $\mathrm{MeHg}$ concentration, which was not the case. This observation is particularly interesting because it means that the SE seems to reflect the effect, and not the concentration, of the MeHg as a contaminant, an effect that is neutralized by dietary Se as indicated by Yamashita et al. [11] and Ralston et al. [23] and therefore 
supports the recommendation of using the biological system's SE as a BWS [12]. These results also support Ralston et al.'s [10,23] and Yamashita et al.'s [11] proposition regarding the importance of considering the Se:Hg ratio as the parameter of relevance to determine the toxicity of foods and feeds and not the $\mathrm{Hg}$ concentration alone.

Table 6. Estimates of the simple linear regressions $\left(y=\beta_{1} \times x\right)$ calculated to observe the trend of the normalized difference between the SE values for the response to the event minus that of the basal state (dependent variable, y) over time (independent variable, $x$ ) from the initial condition at the beginning of the experimental period (SE of the basal state for each group on the 2nd day $=100 \%$ ). A significant regression equation was found in $C_{1}(F(1,6)=16.73, p<0.01)$, with an $R^{2}$ of 0.736 . A significant regression equation was found in $C_{2}(F(1,6)=6.682, p<0.05)$, with an $R^{2}$ of 0.527 . A significant regression equation was not found in $C_{3}$. A significant regression equation was found in $\mathrm{C}_{4}(\mathrm{~F}(1,6)=7.092, p<0.05)$, with an $\mathrm{R}^{2}$ of 0.542 .

\begin{tabular}{|c|c|c|c|c|c|}
\hline & Group & $\beta_{1}$ & Std. Error & $\mathbf{t}$ & $\mathbf{R}^{2}$ \\
\hline \multirow{2}{*}{ Se:Hg $>1$} & $\mathrm{C}_{1}$ & 1.3803 & 0.3374 & $4.09 * *$ & 0.736 \\
\hline & $\mathrm{C}_{2}$ & 1.2471 & 0.4824 & $2.585 *$ & 0.527 \\
\hline \multirow{2}{*}{ Se: $\mathrm{Hg}<1$} & $\mathrm{C}_{3}$ & 0.3860 & 0.2115 & 1.825 & 0.357 \\
\hline & $\mathrm{C}_{4}$ & 0.6008 & 0.2256 & 2.663 * & 0.542 \\
\hline
\end{tabular}

\section{Conclusions and Future Work}

We have been able to quantify the response of $D$. labrax systems to feeds containing four different Se:Hg molar ratios during 14 days. Each system's normalized basal SE gave more consistent results than the normalized SE of the response to a stochastic event and the evolution over time of both the basal SE and of the difference between the response SE minus de basal SE were appropriate to verify the presence of a toxic effect in the system. However, the effect of the toxicant did not seem to be related to the $\mathrm{Hg}$ concentration alone: it kept a relationship to the Se:Hg molar ratio of the feeds. Thus, the basal SE of the systems with a molar Se:Hg $>1\left(C_{1}\right.$ and $\left.C_{2}\right)$ tended to increase during experimental period while that of systems with a molar Se:Hg $<1\left(C_{3}\right.$ and $\left.C_{4}\right)$ tended to decrease. In addition, the differences in the SE of the basal states minus the SE in response to the stochastic event were less pronounced in the systems fed with molar $\mathrm{Se} \mathrm{Hg}<1$. These results were corroborated by the growth of the fish and support the proposition of using the Se:Hg molar ratios as a more reliable criteria to evaluate the risks of $\mathrm{MeHg}$ exposure than the levels of $\mathrm{Hg}$ alone, as well as the recommendation to use the biological system's SE as a parameter when implementing a BWS for safety and welfare purposes.

We hope that this work can be used as a first step for future investigations to confirm and validate the present results with more species and settings. Further work should focus on (i) testing the longer-term effect of $\mathrm{MeHg}$ contamination as well as the effect of different pollutants (individually and /or in combinations) and doses; (ii) testing alternative data acquisition techniques (sonar, IR) in order to avoid the limitations inherent to video recording [13] and, finally (iii) on analyzing relevant biochemical and physiological parameters on the treated fish in order to understand the interplay between the SE of the biological system and its biological/health status to be able to comprehend the biological meaning of the SE values and tendencies.

Acknowledgments: We wish to thank Grupo Tinamenor (Cantabria, Spain) for providing the European seabass. José Antonio Carrero, of the Department of Analytical Chemistry of the University of the Basque Country, UPV-EHU, measured the concentrations of $\mathrm{Hg}$ and Se in the feeds by ICP-MS. The work was supported by grants from the Spanish MINECO (RTC-2014-2837-2-“SELATUN: Minimización de la problemática del mercurio del atún y valorización del atún como alimento saludable, Programa Retos-Colaboración 2014" and CTM2012-40203-C02-01-“BMW: Biomarcadores estándar de base científica en mejillón para diagnosticar y monitorizar los efectos biológicos de la polución en el Golfo de Bizkaia: implementación de la DEME"), Euskampus 
Fundazioa-Campus of International Excellence (307615SAA2) and from the Basque Government Elkartek Grant KK-2016/00057-“MAROMEGA: Nuevas alternativas para la producción de omega-3 a partir derecursos marinos”. The funding sources had no involvement in the preparation of this manuscript. We would like to express our gratitude to the three anonymous reviewers for their useful comments in order to improve this manuscript.

Author Contributions: H.E. designed the experiment, planned and performed the video recordings, the data processing and analysis and the interpretation of the results, and wrote the manuscript; O.C. contributed to the data analysis, interpretation of the results and drafting of the manuscript; I.M. contributed to the experimental design, interpretation of the results and drafting of the manuscript.

Conflicts of Interest: The authors declare no conflict of interest.

\section{References}

1. Gerland, P.; Raftery, A.E.; Sevcíkova, H.; Li, N.; Gu, D.; Spoorenberg, T.; Alkema, L.; Fosdick, B.K.; Chunn, J.; Lalic, N.; et al. World population stabilization unlikely this century. Science 2014, 346, 234-237. [CrossRef] [PubMed]

2. German Advisory Council on Global Change-WBGU. Governing the Marine Heritage; German Advisory Council on Global Change-WBGU: Berlin, Germany, 2013.

3. Smith, M.D.; Roheim, C.A.; Crowder, L.B.; Halpern, B.S.; Turnipseed, M.; Anderson, J.L.; Asche, F.; Bourillón, L.; Guttormsen, A.G.; Khan, A.; et al. Sustainability and global seafood. Science 2010, 327, 784-786. [CrossRef] [PubMed]

4. Food and Agriculture Organization of the United Nations (FAO). The State of World Fisheries and Aquaculture 2016. Contributing to Food Security and Nutrition for All; FAO: Rome, Italy, 2016.

5. Organisation for Economic Co-operation and Development (OECD). The Ocean Economy in 2030; OECD: Paris, France, 2016.

6. European Food Safety Authority. Scientific Opinion on the Risk for Public Health Related to the Presence of Mercury and Methylmercury in Food; European Food Safety Authority: Parma, Italy, 2012.

7. European Commission. Commission Regulation (EC) No 1881/2006 of 19 December 2006 Setting Maximum Levels for Certain Contaminants in Foodstuffs (Text with EEA Relevance); European Commission: Brussels, Belgium, 2006; Voulme 2006, pp. 5-24.

8. Nasopoulou, C.; Zabetakis, I. Benefits of fish oil replacement by plant originated oils in compounded fish feeds: A review. LWT Food Sci. Technol. 2012, 47, 217-224. [CrossRef]

9. European Commission. Commision Directive (EC) 2010/6/EU of 9 February 2010 Amending the Annex I to Directive 2002/32/EC of the European Parliament and the Council as Regards Mercury, Free Gossypol, Nitrites and Mowrah, Bassia, Madhuca; European Commission: Sofia, Bulgaria, 2010; pp. 29-32.

10. Ralston, N.V.C.; Blackwell, J.L.; Raymond, L.J. Importance of molar ratios in selenium-dependent protection against methylmercury toxicity. Biol. Trace Elem. Res. 2007, 119, 255-268. [CrossRef] [PubMed]

11. Yamashita, M.; Yamashita, Y.; Suzuki, T.; Kani, Y.; Mizusawa, N.; Imamura, S.; Takemoto, K.; Hara, T.; Hossain, M.A.; Yabu, T.; et al. Selenoneine, a novel selenium-containing compound, mediates detoxification mechanisms against methylmercury accumulation and toxicity in zebrafish embryo. Mar. Biotechnol. 2013, 15, 559-570. [CrossRef] [PubMed]

12. Eguiraun, H.; Izagirre, U.; Martinez, I. A paradigm shift in safe seafood production: From contaminant detection to fish monitoring-Application of biological warning systems to aquaculture. Trends Food Sci. Technol. 2015, 43, 104-113. [CrossRef]

13. Eguiraun, H.; Lopez-de-Ipina, K.; Martinez, I. Application of entropy and fractal dimension analyses to the pattern recognition of contamined fish responses in aquaculture. Entropy 2014, 16, 6133-6151. [CrossRef]

14. Eguiraun, H.; López-de-ipiña, K.; Martinez, I. Shannon entropy in a European seabass (Dicentrarchus labrax) system during the initial recovery period after a short-term exposure to methylmercury. Entropy 2016, 18, 1-10. [CrossRef]

15. U.S. Food \& Drug Administration. Mercury Levels in Commercial Fish and Shellfish (1990-2012). Available online: https://www.fda.gov/food/foodborneillnesscontaminants/metals/ucm115644.htm (accessed on 14 November 2017).

16. Shannon, C.E. A mathematical theory of communication. Bell Syst. Tech. J. 1948, 27, 379-423. [CrossRef]

17. Guariglia, E. Entropy and fractal antennas. Entropy 2016, 18, 1-17. [CrossRef]

18. Shannon, C.E. Prediction and entropy of printed English. Bell Syst. Tech. J. 1951, 30, 50-64. [CrossRef] 
19. Eguiraun, H.; López-de-Ipiña, K.; Martinez, I. Evolution of Shannon entropy in a fish system (European seabass, Dicentrarchus labrax) during exposure to sodium selenite $\left(\mathrm{Na}_{2} \mathrm{SeO}_{3}\right)$. In Proceedings of the 2nd International Electronic Conference on Entropy and its Aplications, 15-30 November 2015; Sciforum Electronic Conference Series, Volume 2, 2015, pp. 1-8, doi:10.3390/ecea-2-C006.

20. Martinez, I.; Dreyer, B.; Agersborg, A.; Leroux, A.; Boeuf, G. Effect of T3 and rearing temperature on growth and skeletal myosin heavy chain isoform transition during early development in the salmonid Savelinus alpinus (L.). Comp. Biochem. Physiol. 1995, 112B, 717-725. [CrossRef]

21. Wendelaar Bonga, S.E. The stress response in fish. Physiol. Rev. 1997, 77, 592-625. [CrossRef] [PubMed]

22. Wendelaar Bonga, S.E.; Lock, R.A.C. Toxicants and osmoregulation in fish. Neth. J. Zool. 1992, 42, 478-493. [CrossRef]

23. Ralston, N.V.C.; Raymond, L.J. Dietary selenium's protective effects against methylmercury toxicity. Toxicology 2010, 278, 112-123. [CrossRef] [PubMed]

(C) 2018 by the authors. Licensee MDPI, Basel, Switzerland. This article is an open access article distributed under the terms and conditions of the Creative Commons Attribution (CC BY) license (http://creativecommons.org/licenses/by/4.0/). 